\title{
Always on call
}

Cite as: CMAJ 2017 September 25;189:E1214-5. doi: 10.1503/cmaj.161058

CMAJ Podcasts: article reading at https://soundcloud.com/cmajpodcasts/161058-enc

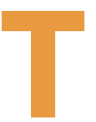
raffic in Summerbrook's dining room peaks at six. On this particular summer evening, we diners were slowly parking our walkers and being ushered to our seats by the concierge, Ann. The spacious room was aglow with warm sun. Waiters and waitresses buzzed back and forth, taking orders, and carrying plates of food and drinks. My wife Jessie and I were seated at the table directly under the chandelier that was occupied by Gary, a newcomer, and Goliath, a friendly clergyman. The special on the menu was turkey schnitzel with soup and salad, and blueberry cheesecake for dessert.

It is customary to mix parties during dinner, and I had come to enjoy an expanded social circle of fellow senior citizens. Gary introduced himself and told us a little bit about himself. We all followed suit with pieces of our history before focusing on our food. Gary stood up suddenly. I reached out to catch the glass of red wine he held in his left hand as he started to tilt. He was blue. With the help of nearby diners, I lowered all six feet four inches of Gary to the floor. I could see he was unconscious. Ann called 911. The ambulance was on its way, so she said. It seemed to me that people were moving in slow motion. I went into physician mode. "Clear the airway," I told myself. "That's your first order of business." As a retired GP, I've resuscitated hundreds of people in my 40-year career, although not one in recent memory.

First, I had to get myself to the floor, too. I crashed down, all 240 pounds of rickety me, my jaw bouncing off Gary's head. I checked his airway for dentures and attempted to clear his airway of a slippery mess of half-chewed schnitzel, beets and potatoes. With the help of a cloth napkin, I managed to clear his airway and started cardiopulmonary resuscitation (CPR). Ann appeared at his other side, cradling the phone. She immediately started cardiac compression at 200 times per minute as instructed by the medical dispatcher. Dr. Jonathon, a retired anesthetist in his $90 \mathrm{~s}$, tapped my shoulder and offered to be one or two minutes. I looked at the kitchen staff and called out for a cardiac defibrillator and a bag-valve-mask ventilator, but all I got was blank stares.

The next 14.5 minutes felt like an eternity. Ann and I did what we could to keep Gary alive. Paramedics arrived in full gear.

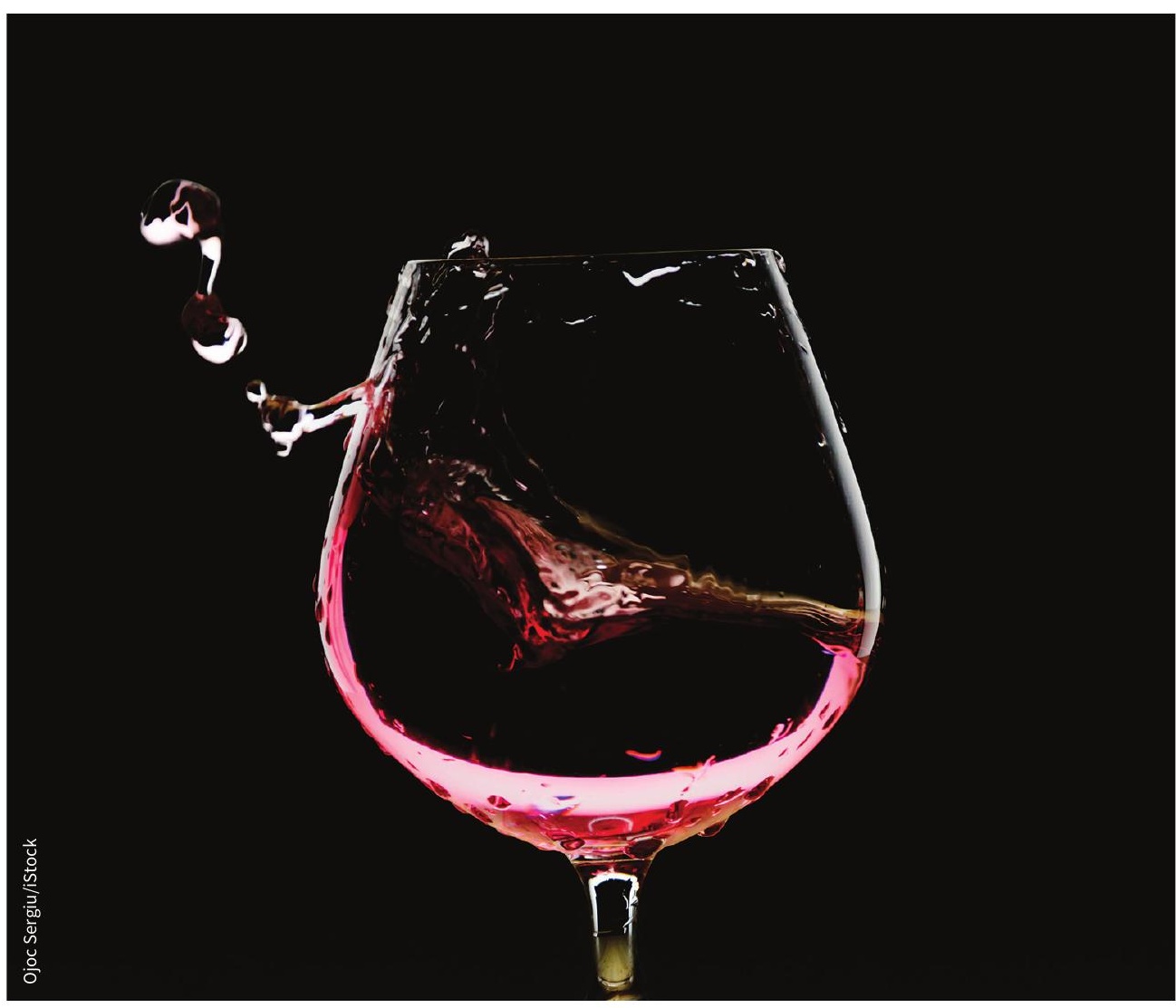

back up. Ann eased up on the cardiac compression while I attempted mouth-tomouth. I wanted a chance to inflate his chest, but Ann informed me that the new protocol was no longer CPR. "We need rapid cardiac compression," she repeated. It was $A B C$ for me: Airway, Breathing, Circulation. So I was dogged. I managed to get 15 to 20 of my breaths into Gary every
Each man was built like a defensive football lineman. I made room for them on the floor. The whole dining room watched while they intubated Gary, started an intravenous line, established an airway with oxygen and defibrillated him twice. When his vital signs were stable, they wheeled him out. Soon sirens blared as they sped off to the hospital. I later 
learned that the cardiologist was ready and waiting. He inserted a stent into the left coronary artery and sent Gary to the intensive care unit. After three black days for Gary, he regained consciousness, beat a bout of pneumonia and returned to independent living at Summerbrook within the month.

After the ambulance left, our waiter, Dick, lifted me to my feet. The staff got me an ice bag for my jaw to reduce the swelling and a dish of ice cream to soothe my nerves. I was exhausted; my fellow diners were dazed. The room started to clear. I talked with Ann who had a late supper and opted for fish rather than schnitzel. I complimented her on her action as a good Samaritan and recommended her for an award from St. John Ambulance.

My swollen face returned to normal, and my sore back responded to hot showers and ibuprofen. Soon, I was back to writing stories, tending my tomato plants and walking my Cairn Terrier.

Whenever I enter the dining room, I look for Gary. I sometimes have dinner with him and his son, Leroy. Gary has regaled me with stories about his life as an airline pilot, and I've offered to help him capture some of them.

Dick tells me that the incident made him rethink his college major. Premed may now be on the menu for him.

An American humourist, Phillip Roth, once said, "old age is not a battle: old age is a massacre." I'm an old soldier now, content with my memories. Ann and I helped Gary make it to his next battle, as I did with so many of my patients. But I'm not sure I need to ride out on the battlefield anymore.

Now, I avoid that table under the chandelier. Never again will I order turkey schnitzel. I rarely order a baked potato or beets. I do, however, reserve the right to change my mind before my 90th birthday.

\section{Sterling Haynes MD}

Kelowna, BC

This article has been peer reviewed.

This is a true story and everyone depicted gave consent for it to be told. All names have been changed. 